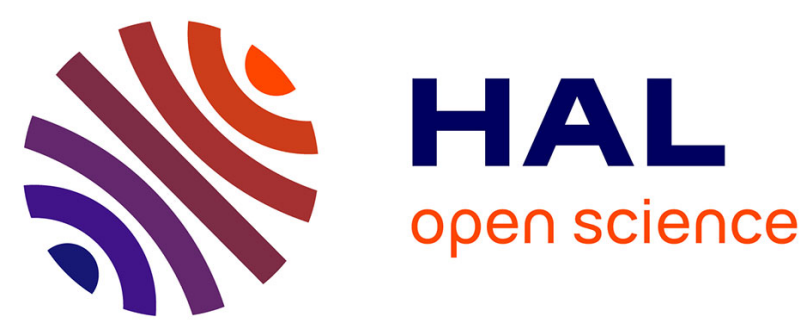

\title{
Exploring the Appropriateness of Different Immersive Environments in the Context of an Innovation Process for Smart Cities
}

Laurent Dupont, Marc Pallot, Laure Morel

\section{- To cite this version:}

Laurent Dupont, Marc Pallot, Laure Morel. Exploring the Appropriateness of Different Immersive Environments in the Context of an Innovation Process for Smart Cities. 22nd ICE/IEEE International Technology Management Conference, Jun 2016, Trondhiem, Norway. 10.1109/ICE/ITMC39735.2016.9025965 . hal-01331887

\section{HAL Id: hal-01331887 \\ https://hal.science/hal-01331887}

Submitted on 15 Jun 2016

HAL is a multi-disciplinary open access archive for the deposit and dissemination of scientific research documents, whether they are published or not. The documents may come from teaching and research institutions in France or abroad, or from public or private research centers.
L'archive ouverte pluridisciplinaire HAL, est destinée au dépôt et à la diffusion de documents scientifiques de niveau recherche, publiés ou non, émanant des établissements d'enseignement et de recherche français ou étrangers, des laboratoires publics ou privés. 


\section{Exploring the Appropriateness of Different Immersive Environments in the Context of an Innovation Process for Smart Cities}

\author{
Laurent Dupont*, Laure Morel \\ ERPI - Equipe de Recherche sur les Processus Inovatifs \\ Université de Lorraine \\ Nancy, France \\ \{1.dupont, laure.morel\}@univ-lorraine.fr
}

\author{
Marc Pallot \\ Presence \& Innovation Lab \\ Arts \& Metiers ParisTech \\ Paris, France \\ marc.pallot@ensam.eu
}

* Corresponding author

\begin{abstract}
This paper presents an explorative study dedicated to the evaluation of immersive environments engaging different stakeholders that have to collaborate within an innovation process in the area of smart cities supported by a dedicated Fab Living Lab platform. A previous study has unveiled the great potential of close-to-real-life immersion perceived by users/citizens in realistic environments that not only fulfill the "realism" principle of a Living Lab but also greatly contribute to both phenomena of technology acceptance and adoption of the proposed solution. Scholars have previously identified three main factors characterizing an immersive environment: the perceived degree of immersiveness, presence and engagement of users. However, creating close to real-life simulated city environments that provide an appropriate immersiveness, presence and engagement remains a challenge. Furthermore, the traditional working habits of smart cities stakeholders, such as: territorial engineers, town-planners and policy makers, are not prepared for behaving properly in immersive environments. Several experiments were carried out during different events that provided both quantitative and qualitative data through the use of surveys, interviews and observations. For each experiment, several immersive equipment were used. The findings highlight the complementarity between physical and digital technologies supporting co-creation for smart city projects, and the advantage of enabling experts in a field to discover new technologies. Finally, this study provides valuable elements on how to better support close to real-life simulated city environments while providing a higher level of stakeholders' engagement during the ideation of the cocreation stage of the innovation process supported by a Fab Living Lab towards the realization of smart cities.
\end{abstract}

Keywords - virtual-reality, immersive-environment, openinnovation, fab-living-lab, user-centered design, co-creation, design, user experience

\section{INTRODUCTION}

A previous paper [1] presented the outcomes of an empirical study dedicated to the role of physical mock-ups supporting users/citizens co-creation activities and anticipation of the User eXperience (UX) [2] within a dedicated urban Living Lab (LL) [3]. The presented findings unveiled the great potential of close-to-real-life immersion of users/citizens in realistic environments that do not only fulfilled the "realism" principle but also greatly contributed to the adoption of the proposed solution by users/citizens. Finally, this previous study provided some elements to support citizens' engagement in the co-creation stage of the urban design process towards the realization of smart cities.

As a follow-up, this paper presents an explorative study on immersive platforms enabling a comparison of users/citizens perceived degree of "realism" principle. As earlier mentioned, since 2011, our research team and the town-planning team of the Greater Nancy designed a process with three stages [4]. However, this approach requires new tools and technologies in order to engage all various stakeholders in the process. The ability to share knowledge among territorial engineers and users/citizens allows developing new practices [5].

Therefore, the main objective of this study is to explore different immersive technologies, observe users behavior and compare the users' perceived satisfaction. Overall, this study is intended to foresee which immersive solution would be the most appropriate at a certain stage of the innovation process supported by a Fab Living Lab platform; such as the Lorraine Fab Living $\mathrm{Lab}^{\circledR}$ (LF2L, founded in 2014), a research platform for prospective assessment of innovative usages [6]. According to previously described 2D (concept), 3D (object), 4D (over time) approaches, the developed process increases interfaces involving users in prospective assessment of innovative usages and accelerates the deployment of industrial or urban demonstrators. 


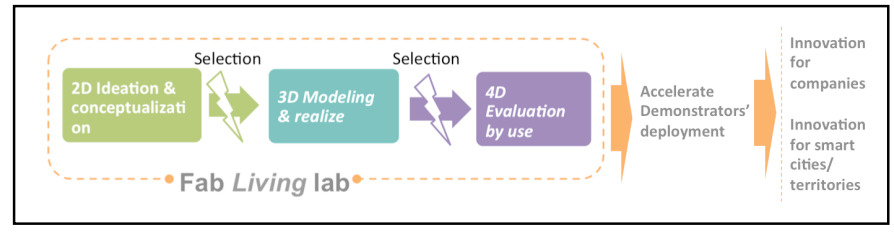

Fig. 1. Model of the smart city innovation flow supported by the Fab Living Lab process

Beside a literature review underlining different concepts related to open innovation in section 2; section 3 presents the developed protocol through an empirical approach using the Fab Living Lab platform. Section 4 describes the collected quantitative and qualitative data and findings obtained during three events. Finally, section 5 further discusses immersive solutions for engaging citizens in smart cities related innovation projects.

\section{RELATED THEORIES AND PREVIOUS WORK}

\section{A. Open Innovation, Living-Lab and Smart Cities}

Scholars [7]-[9] intended to identify and better understand boundary conditions for successful Urban LLs to support smart city. This research implemented the same approach for designing projects within our Urban LL [10], [11]. Further to these considerations, validation in the context of real-life experiments is the essence of the LL approach including external constraints of the usage situation.

Previous papers [5], [8], [12] have already introduced open innovation and the Living Lab approach. New design methods [1], [4], [5] shift the priority towards co-creating value with users in order to ensure a higher rate of technology acceptance and product/service adoption. Curley \& Salmelin [13] recently promoted user co-creation as a vital ingredient of the Open Innovation 2.0 paradigm: "User-driven innovation is a crucial part of the OI2 paradigm and is also a key lever for adoption because users co-create solutions that meet their needs."

However, it requires all stakeholders, especially users/citizens, to be engaged along the design process for co-creating, exploring, experimenting and evaluating product/service scenarios [4], [5]. While these activities are intended to better support the identification of value elements, project stakeholders expect certain value elements for supporting their potential adoption including UX factors [2].

The concept of smart cities is underlined by the prominent role of the Internet, which turned to be a commodity like electricity, and user-driven innovation [14] through FabLabs and Living-Labs operating in the city [11], [15]-[20]. Furthermore, the notion of empowerment of citizens and "democratic innovation" [21] should be embedded in the concept of smart cities. As earlier mentioned by scholars, specific aspects, such as: smart economy, smart mobility, smart environment, smart living, smart people, and smart governance are key characteristics of smart cities [16]. These characteristics allow defining rankings based on measurable underlying indicators.
According to Komninos and colleagues [16], Smart cities can be viewed as mapping between the digital or virtual world (sensors, embedded devices, large data sets, and real-time information and response) and the physical or real world in which smart cities are understood as places generating a particular form of spatial intelligence and innovation.

Two domain landscapes, Living Lab and Future Internet research areas [14], [18] allowed drafting the emerging Smart City landscape and policy roadmaps [15], [19]. All these landscapes convey valuable insights for situating Living Labs between the technology push of Future Internet testbeds and the application pull of smart cities [16].

\section{B. User Co-creation and User eXperience}

While the powerfulness of the concept of co-creation was highlighted by Ramaswany and Gouillard [22], integrating Living Labs and Future Internet for co-creating smart cities services with users/citizens was demonstrated in several EU research projects [20].

In the meantime, UX [23] became the essential evaluation component of the User Driven innovation (UDI) in order to anticipate the perceived user experience, and foresee the level of technology acceptance and solution adoption [2].

\section{C. $\quad V R, A R, M R$ and Immersive eXperience}

In this paper, immersion is considered as the perception of being physically present in a simulated reality (nonphysical world). Virtual Reality (VR), Augmented Reality (AR) and Mixed Reality (MR) technologies constitute different immersive platforms [24]. While UX benefits an ISO definition, the concept of immersive experience (UX in immersive virtual environments) is for $\mathrm{Wu}$ et al. [25] a dichotomy of UX in two parts, namely: Quality of Service (QoS) and Quality of Experience (QoE). Considering a collective UX in immersive environments, Pallot et al. [24] propose an enriched version of Wu's model in order to include social interactions in this context of immersive environments.

According to Bjork and Holopainen [26], there are four categories of immersion, namely: sensory-motoric (e.g. detecting affordances), cognitive (e.g. mental challenge), emotional (e.g. feeling a story) and spatial (e.g. perceptually convinced of being there). Presence, or tele-presence highly depends on QoS factors, such as: latency, frame-rate or optical calibration [25]. The notion of full immersion is conveyed when the five senses (sight, sound, touch, smell and taste) perceive the simulated reality as physically real. Immersive technologies usually fool three senses through visual, auditory and tactile channels. Olfactory and gustation channels are much more complex and limited in their digital implementation. Besides fooling senses, users need also to interact with the simulated environment in an intuitive and natural way (tactile, gestural, motion capture). Some people are more subject to simulation symptoms such as motion sickness due to the situation of the user's body being immobile while moving in the virtual scene; several motion platforms were recently (e.g. treadmill) created for enabling 
users to walk getting the illusion of moving in their environment. Other Virtual reality platforms such as CAVE (Cave Automatic Virtual Environment) allow users to really move within a limited physical space of a room-sized cube.

According to previous studies [27], [28], an immersive experience highly depends on the degree to which a person is engaged. Pallot et al. [24] describes the psychological flow [29] as representing the feelings of someone acting with complete engagement procuring the perception of great enjoyment and sense of control; activities such as reading, gaming or sporting provide an intense feeling of immersion as a natural flow of mind. Enjoyment is a hedonic feeling. Usage time, and the desire to reuse are good cues of the enjoyment felt during an experience [30]. Hence, Pallot et al. [24] considers that an immersive experience depends on the degree of immersion (number of tricked senses) and reflects concurrently the user's perceived degree of presence, engagement and enjoyment; where, respectively, users get the feeling that technology, time and burden disappear.

\section{RESEARCH APPROACH}

The main objectives of the previous study focused on the issues related to a physical mock-up. This paper, as a step further, explores the appropriateness of different alternative immersive environments. The context of an innovation process for Smart cities involves a specific empirical approach supported by a Fab Living Lab platform.

\section{A. Scope}

This first step allows identifying roles and limits of mock-ups to achieve Living lab for a Smarter City. Immersive environments are used as a framework to analyze the previous findings from the role of mock-up during citizens' workshops.

\section{B. Technological context of development}

Citizens' workshops are hosted and supported by the LF2L platform. The LF2L innovation process [6] is used as a model to complete our first experimented Smart City process.

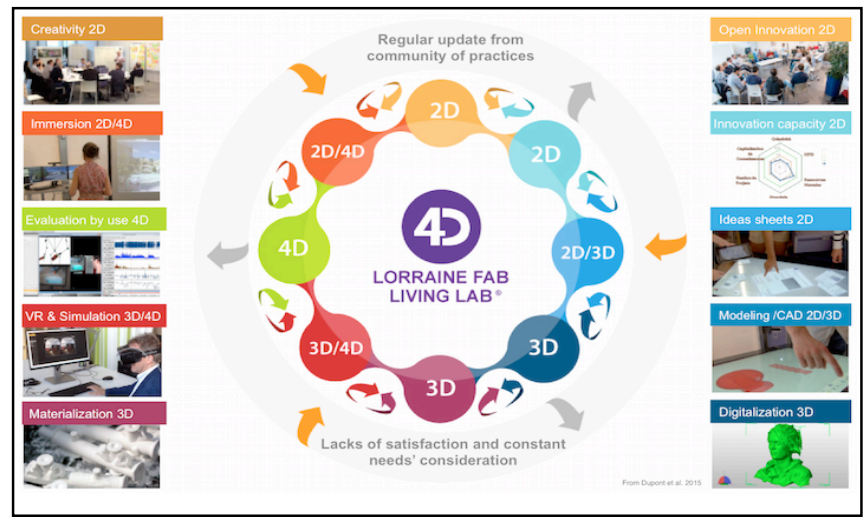

Fig. 2. the $4^{\text {th }}$ Dimension of innovation, updated from [6]
Innovation Capacity 2D stage - evaluates innovative processes to select adapted ideas; Ideas sheets 2D stage allows visualization and selection of ideas; Modeling 2D/3D stage - enables ideas drawing; Digitalization 3D stage allows virtualizing reality; Materialization 3D stage supports ideas concretization; VR \& Simulation 3D/4D stage - generates new environment; Evaluation by use 4D stage - allows to experiment; Immersion 2D/4D stage enables to understand the context, connect to the reality, and share with stakeholders.

The LF2L platform provides resources to design different Immersive Environments in the context of an innovation process dedicated to smart cities. For this paper, researchers experiment the following three environments (Fig.3):

- "Virtual urban stroll" in "immersive bubble" for 2D/4D stage,

- Virtual building visit with a Head Mounted Display (HMD) for 3D/4D stage,

- Interactive map on multitouch table for $2 \mathrm{D} / 3 \mathrm{D}$ stage.

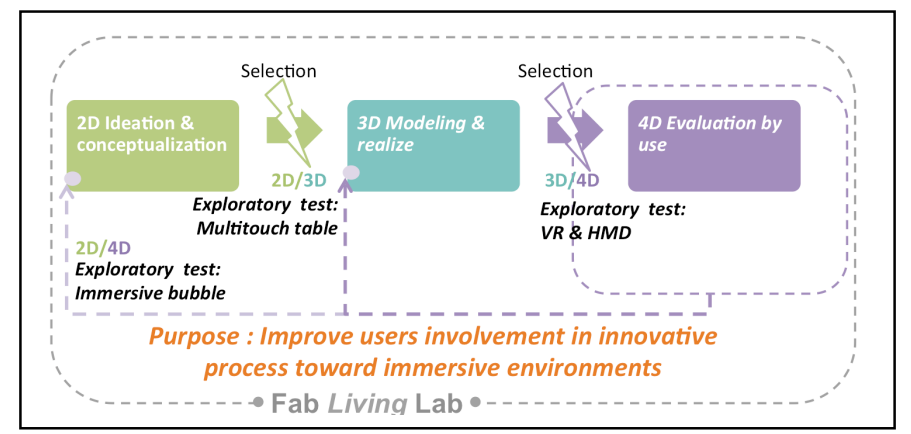

Fig. 3. Model of reinforced LF2L process supported by immersive environments at three specific stages (2D/3D-3D/4D-2D/4D)

\section{Subjects}

For this explorative study, researchers decided to select participants already familiar with urban issues. Indeed, this strategy reduces the distance between the topic (urban projects for smart city) and the users that are skilled in this field. In this study, the main objective consists in focusing on the impact of new technology on the urban project stakeholders. Three alternative situations were generated for engaging project stakeholders.

In October 2015, an Immersive bubble, a HMD and a multitouch table were installed at the French National Congress of local public enterprises. A total of 1500 persons were expected for this 2 days event; and Greater Nancy asked the research team to launch a smart city experimentation. However the audience was not captive. Finally, 25 persons accepted to participate and responded to a survey. During this event, hundreds of people have observed and played with the technologies and exchanged with the research team.

In January 2016, an immersive bubble and a HMD were installed this time at the internal regional ERDF, which manages electric power distribution in France, innovative 2 
days. All the 1400 regional members of this national company were invited to discover various technologies and innovation linked to their professional activities. However, due to the high level of diverse solicitations only 5 participants took time to participate and achieve all the proposed immersive experimentations. Many other ERDF employees have only observed the technologies and took information.

In February 2016, the research team greeted 8 public officers of the Ministry of Sustainable development for a half-day special training, allowing them to discover immersive technologies for co-designing urban project.

Finally, participants $(\mathrm{N}=38$, female and male) were aged from 21 to 60 years old $(\mathrm{M}=35,33)$. Various professional fields linked to urban project and city were involved.

\section{Experimental Platform and equipment}

\section{1) Immersive Bubble $2 D / 4 D$}

This immersive equipment was designed to fit with usage needs identified by the facilitators of the citizens' workshops as follow:

- Mobile immersive equipment that could be easily and quickly deployed;

- Provide the most possible intuitive user interface in order to allow novices to appropriate it easily;

- Create conditions for rapid reconciliation and as faithful as possible to the ground reality (urban or rural areas),

- Mobilize limited financial resources in the initial design.

In terms of used technologies: a large inflatable bubble, a motion sensor and the FAAST (see the description below) software for gestural capture, a video projector to generate a wide viewing angle seen by eyes. The motion sensor is located below the wide projection and catches the participants' motions. Some gestures generate commands to Google Street View (GSV), giving the illusion of movement (Fig. 4).

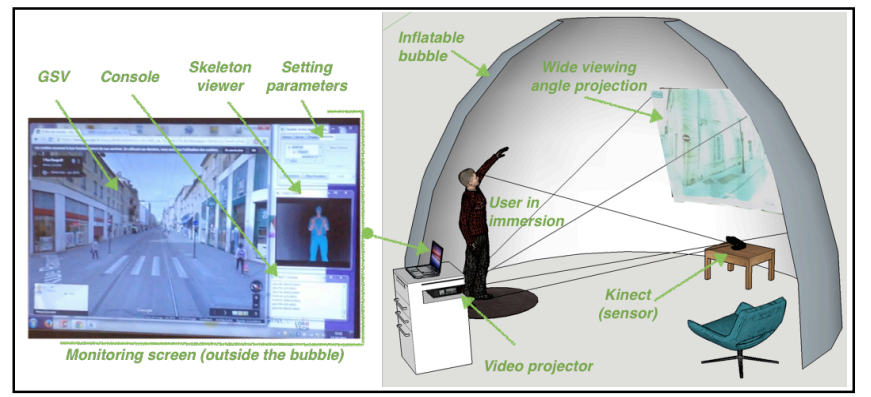

Fig. 4. Schema of the "Immersive bubble" 2D/4D and its monitoring

The FAAST (Flexible Action and Articulated Skeleton Toolkit) software is a middleware that facilitates the integration of the whole body gesture control with games and VR applications using either NI or Open the Microsoft
Kinect software skeleton-tracking windows. In addition, the toolkit allows emulating keyboard inputs triggered by body posture and specific gestures. This allows the user to add custom controls focused on the body gesture. FAAST is for free distribution either for commercial and non-commercial purposes. A monitoring screen is put outside the bubble.

\section{2) Head-Mounted Display (HMD) 3D/4D}

This second immersive equipment is $3 \mathrm{D} / 4 \mathrm{D}$ simulation device. It is based on the use of an Oculus Rift 2. It consists of a stereoscopic head-mounted display (providing separate images for each eye) and head motion tracking sensors. This device seeks to generate virtual environments based on existing or projected environments (Fig.5).

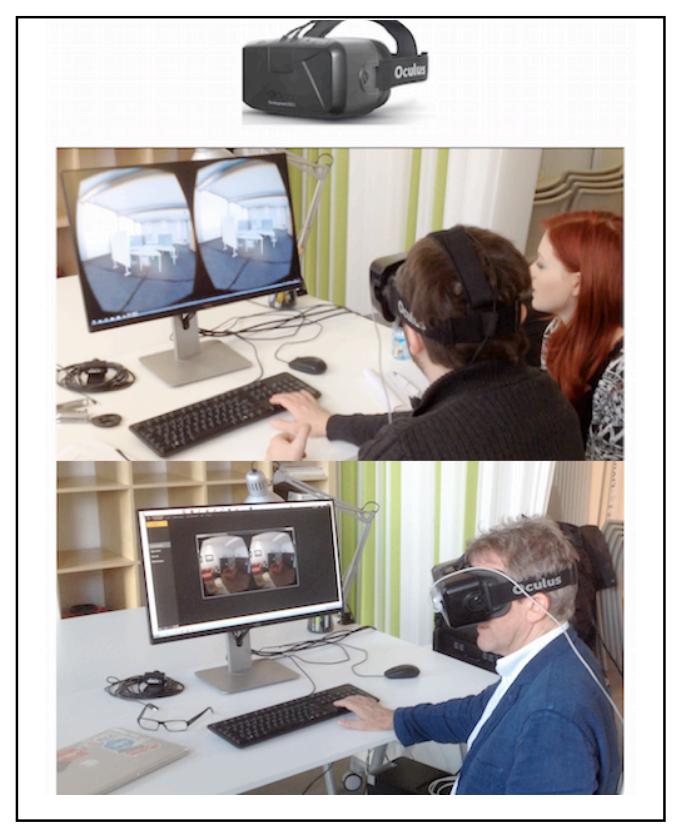

Fig. 5. $1^{\text {st }}$ virtual reality experimentation for 8 public officers of the Ministry of Sustainable development

\section{3) Multitouch table}

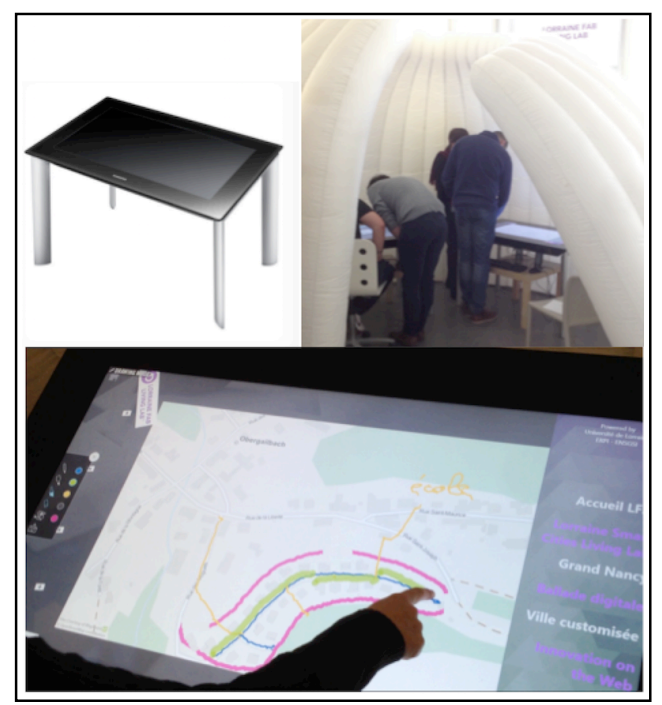

Fig. 6. $1^{\text {st }}$ customized map on multitouch table 
The third immersive equipment consisted in providing a customizable map on a multitouch table. A ground plan resulting from an open street map is used with the "IntuiFace" software designed by Intuilab.

The SUR40 is a multitouch table developed by Samsung and Microsoft. It features a 1080p 40-inch LCD display, and has an AMD Athlon II X2 dual-core processor paired with AMD Radeon HD 6700M graphics. Additionally, the SUR40 is powered with Microsoft Surface and comes with "PixelSense" that allows recognizing up to 50 simultaneous touch-points (Fig.6).

\section{E. Virtual environment}

The hardware of each environment is designed to offer specific experiment to the participants. Different software are used or developed by the LF2L.

The immersive Bubble's environment allows a virtual stroll toward GSV. The users move their arms inside the bubble, and then the FAAST software interprets the user's movements captured by the volumetric camera. Several persons can fit inside the bubble in order to discuss with the participant about the visited virtual space.

The virtualization of LF2L space is offered in the HeadMounted Display. The user can simulate a walk, or fly like a bird because the zero gravity option is activated. There is no sound within this virtual environment. The participant can speak with people close to him/her. The other persons can follow the virtual trip on the large display.

The multitouch table allows working and customizing, e.g. add 3D objects or annotating a map provided by MapQuest based on OpenStreetMap Data. In this case interaction is only with finger touch.

\section{F. Procedure}

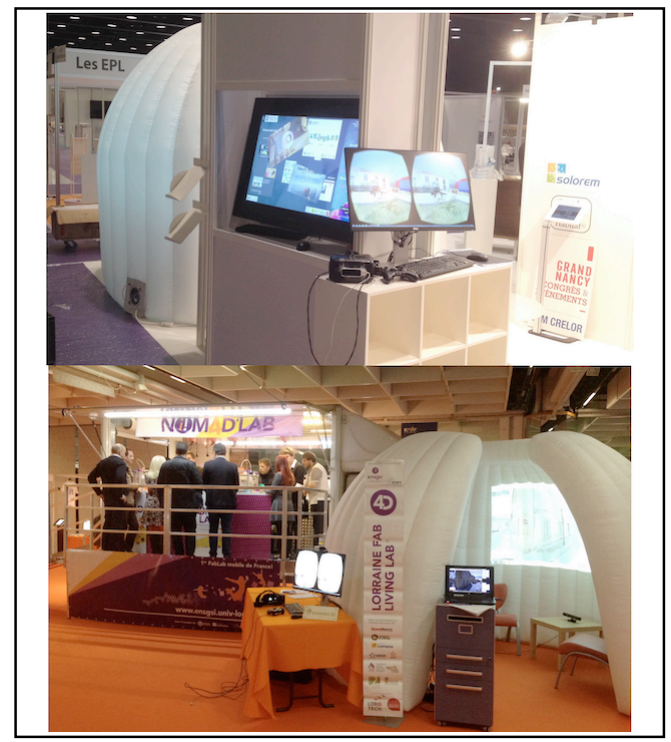

Fig. 7. Immersive platforms experimented during "EPL national congress" and "ErDF innovative days"

First of all, participants are individually confronted to these three immersive platforms in order to foresee their ability to use them. Participants are people working in urban projects. They were involved during specific events dedicated to innovation and smart city (Fig. 7). They experimented different environments. The prior degree of familiarity with diverse digital platforms is an element to consider in the proposed immersive platforms.

\section{G. Evaluation}

To explore the appropriateness of the experimental immersive environments, three methodologies are used to collect data: an explorative survey with investigators or the participant directly answers to the questionnaire; direct observations by researchers; and informal interviews with participants or other interested people.

Collected data allows describing how participants perceived the degree of immersiveness, level of presence and engagement according to the different experimental immersive environments.

\section{FINDINGS}

\section{A. From physical to digital immersive environment}

As describe in a previous paper, four mock-ups were used in citizens' workshops to co-design a generic mobility station: Blueprints and digital model, Scale-model, a room adapted to the real-size dimensions and maps [1]. This research also supported the anticipation of the user experience within a Living Lab and the experimented process for urban living lab allowing to: 1) Transfer technical knowledge (from experts to users); 2) Coordinate stakeholders; 3) Co-create new artifacts; 4) Test some characteristics; 5) Capitalize users expertise / identify usages.

Furthermore, as presented in the table (Tab.I), the above described process allows experts and users generate different types of "knowledge transfer" (second column) for each experimental "1-2-3-4" situations (first column). New types of barriers (third column) also appear for users along the process. For example: 1- Digital model requires technical skills; 2- A physical scale-model is fixed and the scale remains the same; 3- Bodystorming for physically situated brainstorming needs role playing and improvisation in simulated environment; 4- A map requires tacit knowledge because of different layers of abstraction (rotation, orientation, etc.)

TABLE I. TYPE OF KNOWLEDGE AND BARRIERS GENERATED BY FOUR MOCK-UPS, UPDATED FROM [1]

\begin{tabular}{|l|l|l|}
\hline \multicolumn{1}{|c|}{$\begin{array}{c}\text { Observation } \\
\text { source }\end{array}$} & \multicolumn{1}{|c|}{ Knowledge transfer } & \multicolumn{1}{c|}{ Barriers for users } \\
\hline $\begin{array}{l}\text { 1- Digital model } \\
\text { and blueprints }\end{array}$ & $\begin{array}{l}\text { Learning from engineers } \\
\text { and companies }\end{array}$ & Technical know-how \\
\hline 2- Scale-model & $\begin{array}{l}\text { Ideas generation and } \\
\text { creativity }\end{array}$ & $\begin{array}{l}\text { Fixed; One scale = One } \\
\text { mock-up; Top-down view }\end{array}$ \\
\hline 3- Bodystorming & $\begin{array}{l}\text { Understand the others' } \\
\text { point of view / share } \\
\text { knowledge }\end{array}$ & $\begin{array}{l}\text { Simulated environment } \\
\text { and scenarios. Realistic } \\
\text { design (e.g. large space - } \\
\text { cost, time, place) }\end{array}$ \\
\hline 4- Localization & $\begin{array}{l}\text { Adjust / make both } \\
\text { robust and effective }\end{array}$ & $\begin{array}{l}\text { Abstract thinking (read a } \\
\text { map) }\end{array}$ \\
\hline
\end{tabular}


TABLE II. CHARACTERIZATION AND RATING AS “IMMERSIVE ENVIRONMENTS” OF FOUR MOCK-UPS FOR CO-CREATION

\begin{tabular}{|c|c|c|c|c|c|c|c|}
\hline $\begin{array}{c}\text { Observation } \\
\text { source }\end{array}$ & DoI & Aff & EnvP & SoP & $\mathrm{SeP}$ & Eng & CD \\
\hline $\begin{array}{lr}1- & \text { Digital } \\
\text { model } & \text { and } \\
\text { blueprints } & \\
\end{array}$ & $\begin{array}{c}0 \\
2 \mathrm{D} \& \text { abstract } \\
\text { view }\end{array}$ & $\begin{array}{c}0 \\
\text { Understand } \\
\text { blueprint }\end{array}$ & 0 & $\begin{array}{c}0 \\
\text { No } \\
\text { interaction }\end{array}$ & 0 & $\begin{array}{c}+ \\
\text { Discovery }\end{array}$ & 0 \\
\hline 2- Scale-model & $\begin{array}{c}+ \\
\begin{array}{c}\text { Top-down view, } \\
\text { touch }\end{array} \\
\end{array}$ & $\begin{array}{c}+ \\
\text { Like a "serious- } \\
\text { game" }\end{array}$ & 0 & $\begin{array}{c}++ \\
\text { Group } \\
\text { interactions }\end{array}$ & 0 & $\begin{array}{c}++ \\
\text { Hand engagement }\end{array}$ & $\begin{array}{c}++ \\
\text { Shared ideas }\end{array}$ \\
\hline $\begin{array}{l}\text { 3- } \\
\text { Bodystorming }\end{array}$ & $\begin{array}{c}++ \\
\text { Real-size view, } \\
\text { touch, } \\
\text { movement }\end{array}$ & $\begin{array}{c}++ \\
\text { Move false } \\
\text { furniture and } \\
\text { inside the space }\end{array}$ & 0 & $\begin{array}{c}++ \\
\text { Group } \\
\text { interactions }\end{array}$ & $\begin{array}{l}\quad++ \\
\text { Users group } \\
\text { inside space }\end{array}$ & $\begin{array}{c}+++ \\
\text { Body engagement }\end{array}$ & $\begin{array}{c}++ \\
\text { Shared ideas }\end{array}$ \\
\hline 4- Localization & $\begin{array}{c}0 \\
\text { Abstract view }\end{array}$ & $\begin{array}{c}+ \\
\text { Read map }\end{array}$ & 0 & $\begin{array}{c}+ \\
\text { Group } \\
\text { interactions }\end{array}$ & 0 & + & + \\
\hline
\end{tabular}

The overview table (Tab.II) presents the four physical mock-ups characterized and rated as "potential immersive environments" for co-creation. Here are the seven expected parameters: the Degree of Immersiveness (DoI) [24]; the degree of engagement (Eng) that allows deducting user's technology acceptation or level of interest; the "level of presence" including four aspects [31]. The first is Action Presence (Aff) that clearly identifies affordances, direct and natural interactions, contents, scenarios, ideas and emotions. The second is Environmental Presence (EnvP) that shows the virtual environment. The third is Social Presence (SoP), which underlines how the participant communicates with other entity (human, virtual, object, etc.) The last one is Self Presence (SeP) that is about how the user perceives her/his presence inside the environment. How VR is two-way (mutual exchange of information between user and immersion). And finally, Living lab for Smarter City requires stakeholders working together, it is the Collaborative Dimension (CD) [4], [10].

Each identified dimensions are used to qualify the physical experimental mock-ups of the previous study [1]. The evaluation is based on the highest observed potential level. The term "+++" is the highest level, while the term "0" means insignificant. Furthermore, qualitative observations are described.

This analysis shows that user's vision is the main engaged sense. However, touch and movement are generated by scale-model and bodystorming. Furthermore, if the scale-model and bodystorming affordances are clear, these objects don't allow urban project real affordance. In this case, EnvP is always " 0 " because experimented mockups are physical. SoP is generated between participants but there are no direct interactions with the environment. $\mathrm{SeP}$ is only possible in real-size environment. The observations made during previous experiments suggest that engagement level is stronger in experiment $n^{\circ} 3$. Finally, collaboration is supported by all the objects but experiments $n^{\circ} 2$ and $n^{\circ} 3$ have a significant influence.

\section{B. Quantitative Data}

A survey resulting from new experiments provide some quantitative data. Figures 8 to 10 show the most interesting elements studied in this paper. If the majority knew and used GSV, a small number of the participants used one or more immersive environments (fig.8). However, it seems with these first empirical results that familiarity had little influence over appropriateness (Fig.9). Sometime, it was easier for participant not familiar with the technology to discover and explore a new environment. This survey also shows HMD is the easiest technology for participants. Immersive bubble (Motion sensor + GSV) appears as the hardest technology to generating a high degree of immersiveness (fig.10). The following qualitative data provide further explanations.

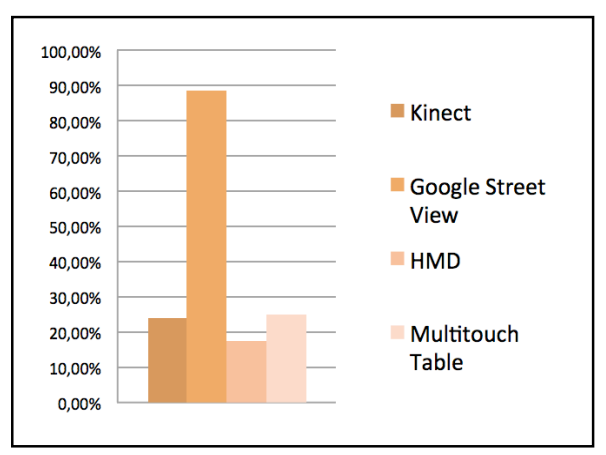

Fig. 8. Number of familiar participant with digital environments in $\%$

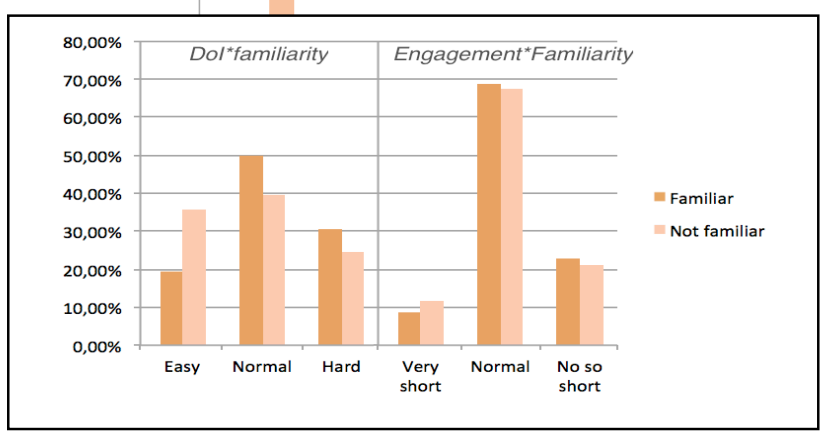

Fig. 9. Degree of Immersiveness (DoI) and Engagement (Eng) (by time velocity) crosses with participants' familiarity (number of participants in \%) 


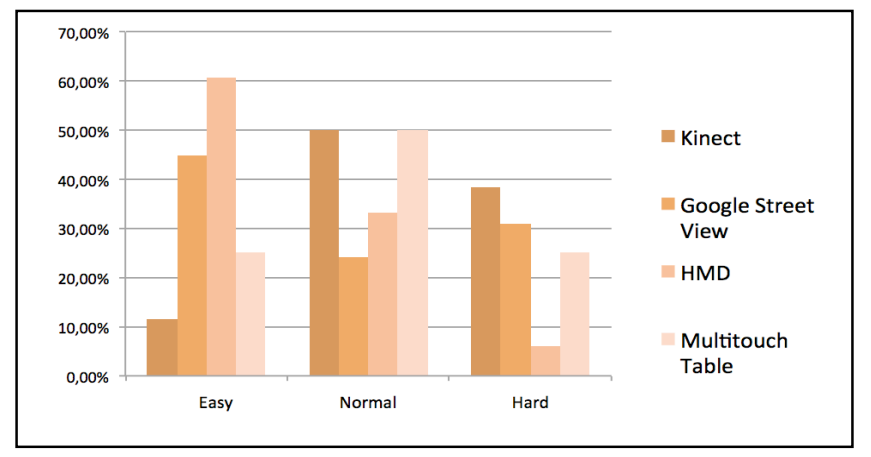

Fig. 10. Degree of immersiveness of each environment according to participants (number of participants in \%)

\section{Increase $L F 2 L$ process}

From the previous Tab.II appears the need to strengthen citizens' workshops using physical artifact and mock-up. These elements are already a few part of LF2L (Tab.III). Indeed, three steps are used in physical dimension: 2D, 3D, 4D. LF2L process and urban living lab context suggest that developing digital solutions could better support Smarter Cities. Thus immersion 2D/4D, VR \& Simulation 3D/4D, and Modeling 2D/3D seem complementary approaches to existing solutions.

TABLE III. PHYSICAL MOCK-UPS AS PART OF THE LF2L PROCESS

\begin{tabular}{|l|l|l|}
\hline \multicolumn{1}{|c|}{$\begin{array}{c}\text { Observation } \\
\text { source }\end{array}$} & Completed LF2L stage & \multicolumn{1}{c|}{$\begin{array}{c}\text { Outside LF2L } \\
\text { resources }\end{array}$} \\
\hline $\begin{array}{l}\text { 1- Digital model } \\
\text { and blueprints }\end{array}$ & $\begin{array}{l}\text { 2D Creativity } \\
\text { 2D/3D Printed modeling } \\
\text { on paper }\end{array}$ & $\begin{array}{l}\text { Blueprints \& pictures } \\
\text { 2D from partners }\end{array}$ \\
\hline 2- Scale-model & $\begin{array}{l}\text { 3D plastic } \\
\text { materialization (scale) }\end{array}$ & $\begin{array}{l}\text { Expensive wood } \\
\text { architectural mock-up }\end{array}$ \\
\hline 3- Bodystorming & $\begin{array}{l}\text { 4D Evaluation by use (in } \\
\text { real-size environment) }\end{array}$ & \\
\hline 4- Localization & 2D Creativity & Map from partners \\
\hline
\end{tabular}

Observations and participants' answers provide qualitative data. A previous analysis shows the trend towards potential appropriateness of the three exploratory immersive environments (Tab. IV). Here, the evaluation is also based on the highest observed potential level with the 38 professional of urban issues, globally not familiar with immersive environments. The term "+++" is the highest level while the term " 0 " means insignificant. Additionally, some comments collected from participants and researchers' observations complete the table.

All immersive technologies have surprised participants to a certain degree. Experiment $n^{\circ} 6$ was seen as very new, futuristic and innovative. Experiments $n^{\circ} 6$ and $n^{\circ} 7$ were really described or used as possible future tools. Nevertheless, a more ergonomic and interactive design is required. Furthermore, many participants were surprised by this new kind of innovative immersive approach for urban project and smart city. Thus, beyond the initial research objective, participants used immersive environments as support to the collective creativity and they were able to imagine future processes for smart city.

Finally, these experimentations allow an iterative analysis of the LF2L process and generate a better process modeling as described in Figure 11. Immersive environments and physical mock-ups are complementary in LF2L context. For each stage it is possible to better describe the necessary sub-objectives, which support smart city demonstrators' deployment. Indeed, physical and virtual mock-ups as well as environments are complementary to design citizens' workshops and better support co-creation. 2D stage with physical mock-up allows sharing initial knowledge, identifying context and giving the framework of the project. $2 D / 3 D$ stage with immersive environment supports group discussion, concepts' strengthening and selection to optimize 3D stage. At this stage, LF2L can design physical mock-ups in multi-material, generates storyboards and technical scenarios. Furthermore, VR of $3 D / 4 D$ stage gives the opportunity to experiment multi-scale and multi-angle scenarios. When VR is not possible or not relevant (delay, cost, etc.), $4 D$ stage organizes evaluation by use as close-to-real-life immersion. Finally, immersive environment of $2 D / 4 D$ stage have to accelerate context understanding and usage-based diagnostic. Involving users during the innovative process toward physical or virtual mock-up and immersive environments, LF2L may reach global purposes: reduce non-acceptance, generate collaboration between communities of practice and communities of interest, encourage appropriation, and enhance sustainable development.

TABLE IV. CHARACTERIZATION AND RATING OF EXPERIMENTED LF2L IMMERSIVE ENVIRONMENTS “2D/4D - 3D/4D - 2D/3D”

\begin{tabular}{|c|c|c|c|c|c|c|c|}
\hline $\begin{array}{l}\text { Observation } \\
\text { source }\end{array}$ & DoI & Aff & EnvP & SoP & SeP & Eng & CD \\
\hline $\begin{array}{l}5-\text { Immersive } \\
\text { bubble for } \\
2 \mathrm{D} / 4 \mathrm{D}\end{array}$ & $\begin{array}{c}+ \\
2 D \text { view }\end{array}$ & $\begin{array}{c}0 \\
\text { Not natural to } \\
\text { walk with hand }\end{array}$ & $\begin{array}{l}+ \\
\text { Picture of the } \\
\text { reality }\end{array}$ & $\begin{array}{c}++ \\
\text { Group } \\
\text { discussion }\end{array}$ & $\begin{array}{c}++ \\
\text { Participant } \\
\text { inside the } \\
\text { bubble }\end{array}$ & $\begin{array}{c}0 \\
\text { Jerky } \\
\text { movements }\end{array}$ & $\begin{array}{c}++ \\
\text { Potential of } \\
\text { communication, use } \\
\text { as demonstrator }\end{array}$ \\
\hline $\begin{array}{l}\text { 6- HMD for } \\
\text { 3D/4D }\end{array}$ & $\begin{array}{c}++ \\
\text { multi-scale \& } \\
\text { multi-angle view }\end{array}$ & $\begin{array}{c}++ \\
\text { better with } \\
\text { gamepad }\end{array}$ & $\begin{array}{l}++ \\
\text { Virtual space } \\
\text { but lake of } \\
\text { sound }\end{array}$ & $\begin{array}{c}++ \\
\text { Interactions } \\
\text { with } \\
\text { observers }\end{array}$ & $\begin{array}{c}+ \\
\text { Not enough, the } \\
\text { participant do } \\
\text { not appear in } \\
\text { the VR }\end{array}$ & $\begin{array}{c}++ \\
\text { Very new, see } \\
\text { as innovative } \\
\text { but motion } \\
\text { sickness }\end{array}$ & $\begin{array}{c}++ \\
\text { Observers can talk } \\
\text { with the participant } \\
\text { and shared his point } \\
\text { of view }\end{array}$ \\
\hline $\begin{array}{l}\text { 7- Multitouch } \\
\text { table for } 2 \mathrm{D} / 3 \mathrm{D}\end{array}$ & $\begin{array}{c}++ \\
\text { Top-down view, } \\
\text { multi-scale touch, }\end{array}$ & $\begin{array}{c}+ \\
\text { Like a wide } \\
\text { tablet but some } \\
\text { commands are } \\
\text { not clear }\end{array}$ & $\begin{array}{c}+ \\
+ \\
\text { Abstraction, } \\
\text { global view }\end{array}$ & $\begin{array}{c}++ \\
\text { Group } \\
\text { interactions }\end{array}$ & $\begin{array}{c}+ \\
\text { Customize the } \\
\text { map, select } \\
\text { options or } \\
\text { scenarios }\end{array}$ & $\begin{array}{c}+ \\
\text { Too sensitive, } \\
\text { the reaction } \\
\text { time is still slow }\end{array}$ & $\begin{array}{c}+++ \\
\text { Co-design and } \\
\text { shared project }\end{array}$ \\
\hline
\end{tabular}




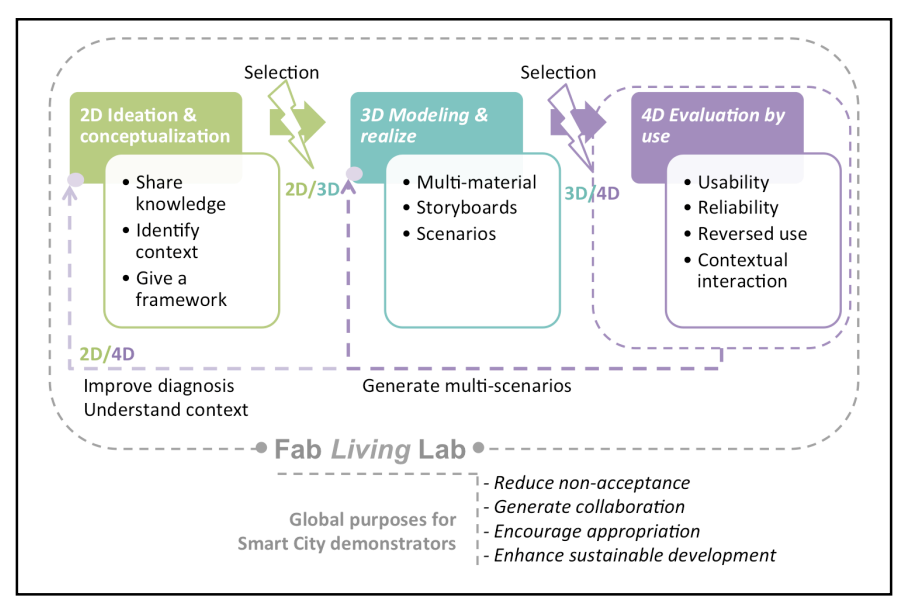

Fig. 11. Expected objectives of each LF2L process' stage

\section{CONCLUSIONS AND FUTURE WORK}

In our previous paper about the design of a participatory process to rebuild an eco-neighborhood in the city center of Nancy [1], our empirical study revealed the paramount role of using a mock-up, as close-to-real-life immersion of users/citizens.

While this type of immersive environment has fulfilled the real-life principles of LL, it greatly contributed to the adoption of an urban mobility station by users/citizens. However, one of the conclusions highlighted the fact that creating close-to-real-life immersive environments, with an appropriate degree of presence, in urban projects according to the objective and stage of the project remains a challenge. Obviously, due to the usual working habits of territorial engineers or town-planners and other stakeholders, they are not necessarily well prepared for evolving within immersive environments. Hence, we concluded that further developing a specific LL design method, based on the use of immersive environments, which is easy to realize and appropriate for all stakeholders, would be necessary.

We do believe that this new study and the use of a Fab Living Lab platform have allowed us to make another step towards a robust LL based participatory design method; it will bring more appropriate solutions to the social and societal stakes of smart cities. This study, based on the comparison between physical and virtual immersive environments, highlighted the great potential of using immersive technologies, such as VR or interactive interfaces, for engaging all urban project stakeholders in a participatory design process. Indeed, it is necessary to further experiment the collaboration support in immersive environments between all project stakeholders, such as: territorial \& urban engineers, town planners, policy makers, social agents and citizens.

As already mentioned in our previous paper's conclusion, in order to validate this participatory design process including immersive environments, the next step would be to evaluate it within different LLs and other urban projects involving users and territorial engineers.

Furthermore, exploring "cheaper" technologies for supporting 3D immersive environments, would be a significant step toward frugal innovation within smart city projects.

\section{ACKNOWLEDGMENT}

Authors thank all the participants of the different experiments, SOLOREM, Grand Nancy Congrès et événements, ErDF, EDUTER and IUVTT students, Hakim Rebiai, and Alizée Scherer for their valuable contributions to this explorative study.

\section{REFERENCES}

L. Dupont, C. Guidat, L. Morel, and N. Skiba, "The role of mock-ups in the anticipation of the user experience within a living lab: An empirical study," in 2015 IEEE International Conference on Engineering, Technology and Innovation/ International Technology Management Conference (ICE/ITMC), 2015, pp. 1-8.

[2] M. Pallot and K. S. Pawar, "A Holistic Model of User Experience for Living Lab Experiential Design," in Proceedings of the 18th International Conference on Engineering, Technology and Innovation, ICE'2012 “Innovation by Collaboration and Entrepreneurial Partnerships,” 2012.

[3] C. Guidat, L. Dupont, N. Skiba, V. Bretagne, M. Camargo, and G. Massouras, "Lorraine Smart Cities Living Lab: white paper on living labs," Institut National Polytechnique de Lorraine (INPL), Nancy, France, Livre blanc remis à la DIRECCTE, 2011.

[4] L. Dupont, L. Morel, J. Hubert, and C. Guidat, "Study case: Living Lab Mode for urban project design: Emergence of an ad hoc methodology through collaborative innovation," in 2014 International Conference on Engineering, Technology and Innovation (ICE), 2014, pp. 1-9.

[5] L. Dupont, L. Morel, C. Guidat, J. Hubert, and M. Revel, "Le « technicien-citoyen » et La Fabrique Nancy Grand Cœur : le prisme de l'usage dans la conception d'un écoquartier," in Mermet, L., Salles, D. (Dir.) "Environnement : la concertation apprivoisée, contestée, dépassée?," Louvain-La-Neuve: De Boeck, 2015, pp. 233-256.

[6] L. Dupont, L. Morel, and P. Lhoste, "Le Lorraine Fab Living Lab : la 4ème dimension de l'innovation," in Actes des sessions du colloque Science \& You, France, 2015, pp. 230-235.

[7] S. Juujärvi and K. Pesso, "Actor Roles in an Urban Living Lab: What Can We Learn from Suurpelto, Finland?," Technol. Innov. Manag. Rev., no. November 2013: Living Labs, pp. 22-27, 2013.

[8] P. Friedrich, A. Karlsson, and M. Federley, "Boundary conditions for successful Urban Living Labs," 2013.

[9] C. Veeckman and S. van der Graaf, "The city as living labortory: A playground for the innovative development of smart city applications," in 2014 International Conference on Engineering, Technology and Innovation (ICE), 2014, pp. 1-10.

[10] L. Dupont, V. Gholipour, L. Morel, J.-C. Bignon, and C. Guidat, "From Urban Concept to Urban Engineering: The Contribution of Distributed Collaborative Design to the Management of Urban Projects," J. Urban Des., vol. 17, no. 2, pp. 255-277, May 2012.

[11] L. Dupont, L. Morel, and C. Guidat, "Innovative public-private partnership to support Smart City: the case of 'Chaire REVES,", J. Strateg. Manag., vol. 8, no. 3, pp. 245-265, Aug. 2015.

[12] H. W. Chesbrough, Open Innovation: The New Imperative for Creating and Profiting from Technology. Boston: Harvard Business School Press., 2003.

[13] M. Curley and B. Salmelin, "Open Innovation 2.0: A New Paradigm," in OISPG White Paper, 2013, pp. 1-12.

[14] M. Pallot, B. Trousse, B. Senach, and D. Scapin, "Living Lab research landscape: from user-centred design and user experience 
towards user co-creation," in Proceedings of the Living Lab Summer School (LLSS), 2010.

[15] N. Kominos, H. Schaffers, and M. Pallot, "Developing a Policy Roadmap for Smart Cities and the Future Internet," in

Proceedings of the eChallenges 2011 Conference, 2011, pp. 1-8.

[16] N. Kominos, M. Pallot, and H. Schaffers, "Special Issue on Smart Cities and the Future Internet in Europe," J. Knowl. Econ., vol. 4, no. 2, pp. 119-134, Jun. 2013.

[17] N. Kominos, M. Pallot, and H. Schaffers, "Open Innovation and Smart Cities," in Open Innovation Yearbook 2013, Luxembourg: Publications Office of the European Union, 2013, pp. 34-41.

[18] M. Pallot, B. Trousse, B. Senach, H. Schaffers, and N. Kominos, "Future internet and living lab research domain landscapes: filling the gap between technology push and application pull in the context of smart cities," in eChallenges e-2011 Conference Proceedings, IIMC International Information Management Corporation, 2011.

[19] H. Schaffers, N. Kominos, M. Pallot, T. Brigitte, M. Nilsson, and A. Oliveira, "Smart cities and the future internet: towards cooperation frameworks for open innovation," Futur. Internet Assem. Lect. Notes, vol. 6656, pp. 431-446, 2011.

[20] H. Schaffers, A. Sallstrom, M. Pallot, J. M. Hernandez-Munoz, R. Santoro, and B. Trousse, "Integrating Living Labs with Future Internet experimental platforms for co-creating services within Smart Cities," in 17th International Conference on Concurrent Enterprising (ICE 2011), 2011.

[21] E. Von Hippel, Democratizing innovation. Cambridge: MIT Press, 2005.

[22] V. Ramaswamy and F. J. Gouillart, The Power of Co-Creation: Build it with them to Boost Growth, Productivity, and Profits. New York: Free Press., 2010.

[23] I. O. for S. (ISO), "ISO 9241-210, Ergonomics of human system interaction - part 2: human-centered design for interactive systems." 2009.

[24] M. Pallot, R. Eynard, B. Poussard, O. Christmann, and S. Richir, "Augmented sport: exploring collective user experience.," in Proceedings of the Virtual Reality International Conference on Laval Virtual - VRIC '13, 2013, p. 1.

[25] W. Wu, A. Arefin, R. Rivas, K. Nahrstedt, R. Sheppard, and Z. Yang, "Quality of experience in distributed interactive multimedia environments: toward a theoretical framework," in ACM Multimedia Conference, 2009, pp. 481-490.

[26] S. Bjork and J. Holopainen, Patterns in Game Design. . Charles River Media, 2004.

27] E. Brown and P. Cairns, "A grounded investigation of immersion in games,” Proc. CHI EA '04, pp. 1297-1300, 2004.

[28] R. Agarwal and E. Karahanna, "Time Flies When You're Having Fun: Cognitive Absorption and Beliefs About Information Technology Usage," MIS Q., vol. 24, no. 4, pp. 665-694, 2000.

[29] M. Csikszentmihalyi, Flow: The Psychology of Optimal Experience. New York: Harper and Row, 1990.

[30] R. Eynard, M. Pallot, O. Christmann, and S. Richir, "Impact of Verbal Communication on User Experience in 3D Immersive Virtual Environments," in IProceedings of the International Conference on Engineering, Technology and Innovation (ICE), ICE'2015, 2015.

[31] P. Bouvier, "Presence in virtual reality, a user centred approach," Université Paris-Est Spécialité : Informatique Présentée, 2009. 